Relations industrielles

Industrial Relations

\title{
Beyond Industrial Growth, par Abraham Rotstein (éd.), Toronto, University of Toronto Press, 1976, 131 p.
}

\section{Gilles Dussault}

Volume 31, numéro 2, 1976

URI : https://id.erudit.org/iderudit/028716ar

DOI : https://doi.org/10.7202/028716ar

Aller au sommaire du numéro

Éditeur(s)

Département des relations industrielles de l'Université Laval

ISSN

0034-379X (imprimé)

1703-8138 (numérique)

Découvrir la revue

Citer ce compte rendu

Dussault, G. (1976). Compte rendu de [Beyond Industrial Growth, par Abraham Rotstein (éd.), Toronto, University of Toronto Press, 1976, 131 p.] Relations industrielles / Industrial Relations, 31(2), 326-326.

https://doi.org/10.7202/028716ar

Tous droits réservés @ C Département des relations industrielles de l'Universite Laval, 1976
Ce document est protégé par la loi sur le droit d'auteur. L’utilisation des services d'Érudit (y compris la reproduction) est assujettie à sa politique d'utilisation que vous pouvez consulter en ligne.

https://apropos.erudit.org/fr/usagers/politique-dutilisation/ 
Beyond Industrial Growth, par Abraham Rotstein (éd.), Toronto, University of Toronto Press, 1976, 131 p.

La croissance industrielle du monde occidental peut-elle continuer longtemps à son rythme actuel? Comment prévenir l'épuisement prochain des ressources non-renouvelables? Comment éviter que soient pollués sans retour possible nos mers, notre atmosphère, nos terres? Comment, en même temps, allons-nous réduire les écarts criants entre riches et pauvres? Comment stopper la multiplication des situations conflictuelles que génère une croissance désordonnée? Voilà autant de questions soulevées par les ouvrages du Club de Rome que le Massey College de Toronto a proposé à six conférenciers de renom comme toile de fond d'une interrogation sur les limites de la croissance industrielle.

Le sénateur Maurice Lamontagne, dans un texte bien documenté, pose le problème du fonctionnement global de la société rendu de plus en plus difficile par le fait que les institutions ne sont pas adaptées au rythme de croissance exponentielle que nous connaissons depuis la révolution industrielle. Il convient, selon lui, de repenser les mécanismes de prise de décisions collectives et d'institutionaliser la planification à long terme comme mode de gestion des ressources, en remplacement des politiques, à courte vue, traditionnelles.

Le président de Radio-Canada, M.A.W. Johnson, reprend également cette idée de la nécessité d'une vision planifiée de l'avenir. Il analyse le phénomène de croissance du point de vue de l'économiste et invite à une vision élargie de l'économie qui tienne compte de ses dimensions sociales et politiques.

M. Claude Castonguay et Charles Taylor s'interrogent sur l'évolution des structures politiques et se demandent à quelles conditions pourra être assuré l'exercice démocratique du pouvoir dans la société de demain. Tous deux s'accordent pour dire que c'est par une participation accrue des citoyens aux décisions collectives que pourront être préservés les fondements de la démocratie. M. Castonguay insiste pour dire que là où le défi de la participation sera le plus grand, c'est dans le monde du travail où les structures de pouvoir héritées du libéralisme des débuts de la révolution industrielle sont les plus difficiles à modifier.

Deux autres conférences de Vivian Rakoff, psychiatre de l'Université de To- ronto, et de Georges Grant, professeur de religion à McMaster, complètent cet ouvrage dont l'objectif est essentiellement de familiariser, par le biais de conférences de qualité, un vaste public avec des interrogations qui deviennent de plus en plus centrales dans les débats sociaux actuels.

\section{Université Laval}

\section{Gilles DUSSAULT}

The Quality of Working Life, par Louis E. Davis et Albert B. Cherns (éd.), Vol. 1: «Problems, prospects and the State of the Art», Vol. II: "Cases and Commentary », New-York, The Free Press, $450 \mathrm{p}$ et $387 \mathrm{p}$.

Le thème de la qualité de vie de travail est appelé à prendre de plus en plus de place parmi les préoccupations des travailleurs, des employeurs, et des gouvernements. Des indications très nettes démontrent une désaffection des travailleurs, surtout chez les plus jeunes à l'égard des tâches bureaucratiques. Les taux de roulement et d'absentéisme élevés, la multiplication des conflits spontanés, des sabotages, ne laissent pas beaucoup de doutes sur la nécessité de repenser les milieux de travail, pour paraphraser Jacques Grand-Maison. Dans nos sociétés qui se disent et se veulent toujours plus démocratiques, l'autoritarisme des structures industrielles fait plus que jamais figure d'anachronisme et devient forcément source de problèmes.

Les travailleurs sont insatisfaits, les employeurs trouvent leurs entreprises de plus en plus ingouvernables, les gouvernements sont aux prises avec des conflits qui ne cessent de s'additionner les uns aux autres et dont la tendance à se radicaliser ne semble pas s'amenuiser: que faire?

Voilà une question qui mobilise de nombreux chercheurs et qui devient centrale pour les spécialistes des relations industrielles.

Dans un effort pour jeter un éclairage pertinent sur les questions reliées à la qualité de la vie de travail, les professeurs Louis E. Davis, du Center for Quality of Working Life (UCLA) et Albert E. Cherns, membre du Council of Tavistock Institute ont publié un ouvrage de haute qualité qui fait le point sur le développement de la recherche dans ce domaine.

Ils ont d'abord réuni, dans une conférence internationale à New-York à l'au- 